\title{
A Severe Hypokalemia Case Due to Ectopic Acth Syndrome Secondary to Small Cell Lung Cancer
}

\author{
Edip Erkus ${ }^{*}, 1$, M. Zahid Kocak ${ }^{1}$, Gulali Aktas ${ }^{1}$,Emine Ozsari², Selma E. Duzcu ${ }^{3}$, Tuba T. Duman ${ }^{1}$, \\ Burcin M. Atak ${ }^{1}$, Haluk Savli ${ }^{1}$ \\ ${ }^{\text {I} A b a n t ~ I z z e t ~ B a y s a l ~ U n i v e r s i t y ~ H o s p i t a l, ~ D e p a r t m e n t ~ o f ~ I n t e r n a l ~ M e d i c i n e, ~ B o l u, ~ T u r k e y . ~}$ \\ ${ }^{2}$ Abant Izzet Baysal University Hospital, Department of Pulmonology, Bolu, Turkey. \\ ${ }^{3}$ Abant Izzet Baysal University Hospital, Department of Pathology, Bolu, Turkey.
}

\begin{abstract}
Ectopic adrenocorticotropic hormone (ACTH) syndrome is responsible about 15\% of Cushing syndrome cases. Malignant tumors, such as, small cell lung cancer, gastric or bronchial carcinoids, pheochromacytoma, medullary thyroid cancer, are principle causes of ectopic ACTH secretion. Syndrome manifest with impaired glucose tolerance or overt diabetes, hypertension, hypokalemia and lipid disorders. Here we report a subject presented with severe hypokalemia due to ectopic ACTH syndrome, who was diagnosed with small cell lung cancer consequently.

A sixty five year old man presented with severe hypokalemia. He was diagnosed with small cell lung cancer. Serum ACTH and cortisol levels of the subject were extremely high. Although chemotherapy initiated, he died due to respiratory failure. Radiologic studies should be ordered to rule out underlying tumoral developments in patients presenting with delirium and hypokalemia. Moreover, hyperglycemia in elderly without prior history of diabetes mellitus should be evaluated for malignant lesions and ectopic release of ACTH.
\end{abstract}

Keywords: Ectopic ACTH syndrome, Small cell lung cancer, Hypokalemia, Fatigue, Pretibial Edema, Diabetes.

\section{INTRODUCTION}

Ectopic adrenocorticotropic hormone (ACTH) secretion makes $15 \%$ of Cushing syndrome cases [1]. Ectopic secretion of ACTH is caused by many cancers including neuroendocrine tumors and small cell lung cancer. As a paraneoplastic syndrome, it is usually associated with small cell subtype of the lung carcinoma [2]. It is characterized with severe hypercortisolemia, despite clinical picture of the patients with ectopic ACTH might not be similar to those with Cushing Syndrome. For instance, hypokalemic metabolic alkalosis may be seen in ectopic ACTH syndrome. However, depression and anxiety disorder may complicate both Cushing disease and ectopic ACTH syndrome.

In present study, we aimed to report a subject that diagnosed with type 2 diabetes mellitus recently, who presented with severe hypokalemia and delirium due to ectopic ACTH syndrome secondary to small cell lung cancer. The case is important to discuss since it shows many of the clinical feature of ectopic ACTH syndrome.

\section{CASE REPORT}

A sixty five year old man presented to our outpatient clinics with weight loss, fatigue, dry mouth, pretibial edema and recently neuropsychiatric complaints; such as hallucination

*Address correspondence to this author at the Abant Izzet Baysal University Hospital, Department of Internal Medicine, Golkoy, 14200, Bolu, Turkey.

E-mail: dr.ediperkus@gmail.com and aggressive behavior. Blood pressures of the patient were $130 \mathrm{mmHg}$ systolic and $80 \mathrm{mmHg}$ diastolic, heart rate was: 86 beats per minute, respiratory rate was 16 breaths per minute and body temperature was 36.5 Celsius degree. He was on metformin $1000 \mathrm{mg}$ twice daily and Gliclazid $30 \mathrm{mg}$ once daily for 2 weeks since he was diagnosed with type 2 diabetes mellitus (15 days before his admission to our clinic). On physical examination, he was delirious and poorly oriented. His facial skin was plethoric and he had prominent bilateral pretibial edema (3+). Bilateral rhonchi and coarse crackles at the basement of right hemithorax were also noted.

A couple of blood tests including hemogram and serum biochemistry conducted and hypokalemia $(2 \mathrm{mmol} / \mathrm{L}$; RR: $3.5-5.5 \mathrm{mmol} / \mathrm{L}$ ) noticed. Results of other laboratory tests were as follows: fasting plasma glucose: $241 \mathrm{mg} / \mathrm{dl}$, c-reactive protein: $31 \mathrm{mg} / \mathrm{l}(\mathrm{RR}): 0-5 \mathrm{mg} / \mathrm{l})$, alanine aminotransferase: $115 \mathrm{U} / 1$ (0-55U/l), aspartate aminotransferase: $78 \mathrm{U} / 1$ (5-34 U/1), lactate dehydrogenase: 943 U/1 (RR: 125-220 U/l), blood urea: $51 \mathrm{mg} / \mathrm{dl}$, creatinine: $0.87 \mathrm{mg} / \mathrm{dl}$, sodium $(\mathrm{Na}): 141$ $\mathrm{mmol} / \mathrm{l}$, chlorine $(\mathrm{Cl}): 95 \mathrm{mmol} / \mathrm{l}$, calcium $(\mathrm{Ca}): 8.4 \mathrm{mg} / \mathrm{dl}$ (RR: $8.4-10.2 \mathrm{mg} / \mathrm{dl}$ ). Intravenous and oral potassium repletion slightly corrected serum potassium levels to 2.9 $\mathrm{mmol} / \mathrm{L}$. Normal serum levels of potassium achieved on $3^{\text {rd }}$ day of treatment.

A hemogram revealed white blood cell count: 14600 cell $/ \mathrm{mm}^{3}$, hemoglobin: $14.6 \mathrm{~g} / \mathrm{dl}$, platelet count: 136000 cell $/ \mathrm{mm}^{3}$. 
Serum cortisol level at 8 am was greater than $59.8 \mathrm{ug} / \mathrm{dl}$ (RR: 3.7-19.4ug/dl) and ACTH level was $199 \mathrm{pg} / \mathrm{ml}$ (RR: 0-46 $\mathrm{pg} / \mathrm{ml})$. Urinary cortisol in 24 hours was greater than $1000 \mathrm{ug}$ (RR: 3.5-45ug). Plasma aldosterone (14.3 ng/ml [RR: $1-16 \mathrm{ng} / \mathrm{ml}])$ and bedside renin $(1.64 \mathrm{ng} / \mathrm{ml} /$ hour [RR:0.5-2.6ng/ml/hour]) levels were in normal range. Arterial blood gas analyze was as follows: $\mathrm{pH}: 7.57, \mathrm{pCO} 2: 46 \mathrm{mmHg}$, pO2: $89 \mathrm{mmHg}$, HCO3: $41 \mathrm{mmol} / 1$, and K: $1.94 \mathrm{mmol} / 1$. These blood gas analyze was consisted with hypokalemic metabolic alkalosis. Indol acetic acid in 24 hours of urine was 47.6 umol/day (RR: 10.4-131 umol/day). A chest radiogram was revealed bilateral hilar fullness, increase in thickness on the right para-tracheal line, mediastinal left deviation, increase in nodal density in the vicinity of the left hilum, increase in the broncho-vascular branch in the lower lung, infiltrative appearance in para-cardiac zone of left lower lung (Fig. 1A).

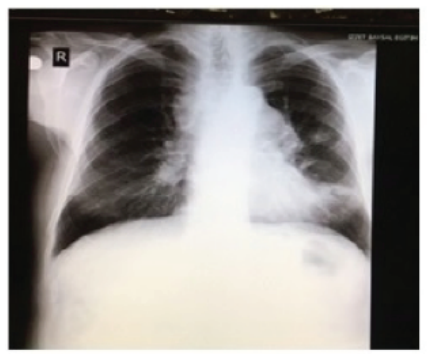

A

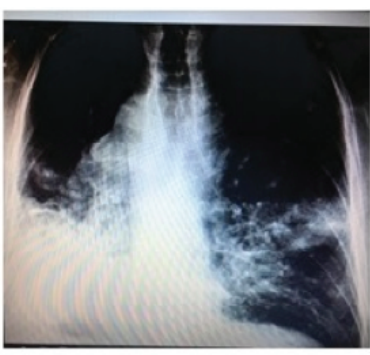

B
Fig. (1). (A) Chest X-ray on the Day of Hospital Admission: Bilateral Hilar Fullness, Increase in Thickness on the Right Paratracheal Line, Mediastinal Left Deviation, Increase in Nodal Density in the Vicinity of the Left Hilus, Increase in the Bronchovascular Branch in the Lower Lung, Infiltrative Appearance in Paracardiac Zone of Left Lower Lung. (B) Chest X-ray after Chemothreapy: Mediastenal Left Deviation, Bilateral Hilar Fullness, Increase in Thickness on Right Paratracheal Line, Increase in Nodular Density in the Vicinity of the Left Hilus, Increase in Infiltration Area in the Left Lower Zone, Closure in the Left Cardiophrenic and Costophrenic Sinuses, the New Infiltration in Middle and Lower Zone of Lung.

Nasal oxygen supplementation, and intravenous antibiotics (Seftriaxone $2 \mathrm{~g} /$ day and Clarithromycin 500mg twice a day) initiated along with oral and parenteral potassium supplement. Malignant appearing mass in left lung $(16 \times 25 \mathrm{~mm}$ irregular contoured soft tissue mass in the anterior segment localization of the left upper lobe of the lung and reticular densities in the periphery), conglomerated hilar and mediastinal lymphadenopathies, 2 nodular lesions in liver and metastatic nodular lesions in bilateral supra renal glands were visualized by thoraco-abdominal computed tomography. Cranial computed tomography and pituitary magnetic resonance imaging were normal.

Bronchoscopy performed and an infiltrative mass in left lung detected. The right pulmonary system was clearly visible until all the lobes and segments were open. The lingular segment was oblitered with mucosal lesion (Fig. 2).

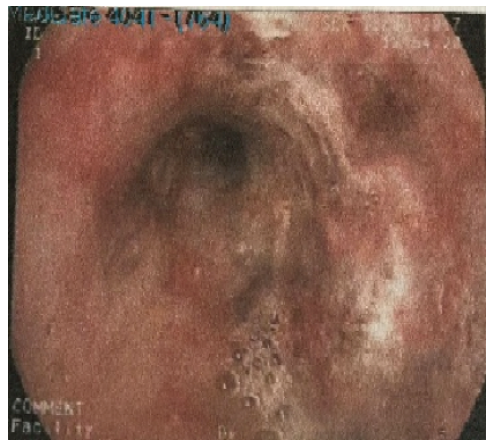

Fig. (2). Mucosal Infiltration and Endobronchial Obliteration of Lingula.

Bronchi of right lung were also obstructed due to external pressure of conglomerated lymph nodes. Microscopic examination of the bronchoscopic biopsy material revealed extensive crush artefact and tumor infiltration in solid islands, which did not constitute a gland structure. Tumor cells were small and ovoid in shape, characterized with narrow eosinophilic cytoplasm and hyperchromatic nucleus without prominent nucleoli (Fig. 3). TTF-1 immunohistochemical staining was positive as suggestive of primary lung cancer and CD56 neuroendocrine staining was strongly positive (Fig. 3).

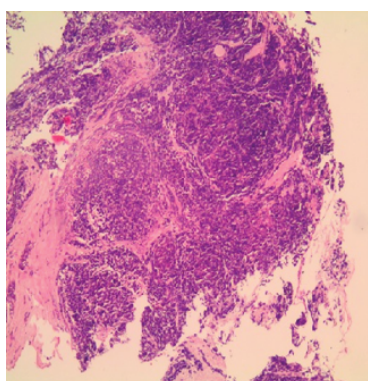

A

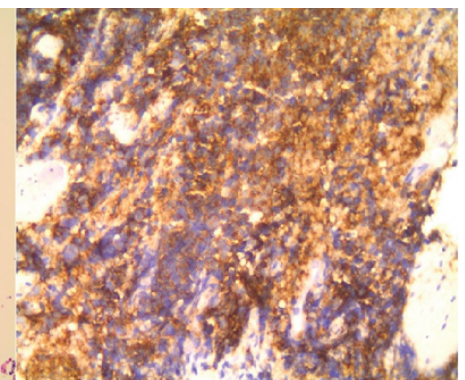

B
Fig. (3). (A) Atypical Cell Islands with Hyperchromatic Nucleus and Narrow Cytoplasm Showing Crush Artefact (HE x200), (B) Positive Staining with CD56 Staining.

Chromogranine staining was focal positive and synaptophisin, CD45, and P63 were negative. A pathologic diagnosis of small cell lung cancer was established according to the morphologic and immunohistochemical staining characteristics of the biopsy material.

A chemotherapy combined with etoposide and cisplatin was initiated. Patient was also started on Spironolactone to antagonize excess mineralocorticoid effect. He complained of dyspnea and his general condition was deteriorated on $2^{\text {nd }}$ day of the treatment. Control chest radiography demonstrated patchy infiltrative lesions suggesting progressed pneumonia 
(Fig. 1B). He was transferred to intensive care unit, however, patient died on $3^{\text {rd }}$ day of chemotherapy due to respiratory failure.

\section{DISCUSSION}

Hypokalemia along with metabolic alkalosis in a patient that diagnosed with type 2 diabetes mellitus recently should prompt medical attention for evaluation of secondary causes of hypercortisolism. Besides, behavioral changes also make the case unique since it shows classic pattern of ectopic ACTH syndrome. Ectopic ACTH syndrome have been reported to be associated with small cell lung cancer [3], pulmonary adenocarcinoma [4], gastric or bronchial carcinoid tumors $[4,5]$, and a various types of malignant diseases including islet cell tumors, malignant melanoma, medullary thyroid cancer and pheochromocytoma [2]. In this report, Ectopic ACTH syndrome was observed in a patient with small cell lung cancer in present report.

Ectopic ACTH syndrome complicates 2-5\% of small cell lung cancer cases and is more common in men, smokers and elderly [6]. Hyperglycemia, hypokalemia and metabolic alkalosis is prominent in subjects with ectopic ACTH syndrome. A study in literature reported hypertension in $88 \%$, diabetes mellitus or impaired glucose tolerance in $75 \%$, dyslipidemia in $69 \%$, hypokalemia in $88 \%$ and severe infection in $44 \%$ of subjects with ectopic ACTH syndrome [7]. Systemic infection rate was reported as high as $35 \%$ in patients with ectopic ACTH syndrome in another study [8]. Severe hypokalemia accompany to ectopic ACTH syndrome in $70 \%$ of the cases [9]. Severity of the hypokalemia was associated with the serum levels of cortisol [10]. Similar to the literature, present case had new onset type 2 diabetes mellitus, severe hypokalemia and infection, which became more severe after chemotherapy.

Serum ACTH level is much more increased in ectopic ACTH syndrome compared to Cushing Disease. Moreover, circulating ACTH and cortisol levels are extremely elevated, the onset of symptoms is more recent and the clinical phenotype is atypical in subjects with ectopic ACTH syndrome caused by ACTH production from malignant tumors in comparison to pituitary ACTH over secretion [10].

Plasma cortisol is very increased and diurnal rhythm is diminished. Similarly, urinary free cortisol levels are very high in ectopic ACTH syndrome. Increased levels of cortisol do not suppress during high dose dexamethasone suppression test [11]. Hypokalemia, hyperglycemia, metabolic alkalosis, elevated serum cortisol and ACTH levels and increased urinary free cortisol in present case were all consisted with literature knowledge.

Inferior petrosal sinus sampling is indicated in differential diagnosis of Cushing Disease. We did not performed this invasive procedure due to the poor clinical condition of the patient. On the other hand, increased serum ACTH and cortisol, typical laboratory findings of the syndrome, malignant mass in left lung in thorax CT, hepatic and supra renal metastatic lesions and normal pituitary MRI suggested Ectopic ACTH syndrome in present case.

Removal of the tissues secreting ectopic ACTH is the standard or ideal treatment of ectopic ACTH syndrome. However, surgical excision is usually not possible in these cancers. Luckily, they are chemo-sensitive tumors and we initiated chemotherapy in present case without any delay.

Infection is a common problem in subjects with ectopic ACTH syndrome that received chemotherapy [12]. Present patient was admitted with pneumonia and received Clarithromycin plus ceftriaxone. Clinical and laboratory response was obtained and chemotherapy initiated afterwards. Blood cultures of the patient were negative. However, respiratory failure developed consequently due to advanced pneumonia.

\section{CONCLUSION}

Ectopic ACTH syndrome is usually associated with small cell lung cancer. Delay in the diagnosis increases morbidity and mortality in this population. Radiologic studies should be ordered to rule out underlying tumoral developments in patients presenting with delirium and hypokalemia. Moreover, hyperglycemia in elderly without prior history of diabetes mellitus should be evaluated for malign lesions and ectopic release of ACTH.

\section{CONFLICT OF INTEREST}

Declared none.

\section{ACKNOWLEDGEMENTS}

Declared none.

\section{REFERENCES}

[1] BE J. Paraneoplastic Syndormes. In: Wilson JD, Isselbacher KJ, Kasper DL, Eds. Harrison's Principles of Internal Medicine. New York, USA: McGraw-Hill Inc. 1998; pp. 618-27.

[2] Beuschlein F, Hammer GD. Ectopic pro-opiomelanocortin syndrome. Endocrinol metabolism Clin North Am 2002; 31(1): 191-234. DOI: 10.1016/S0889-8529(01)00025-1

[3] Ilias I, Torpy DJ, Pacak K, et al. Cushing's syndrome due to ectopic corticotropin secretion: Twenty years' experience at the National Institutes of Health. J Clin Endocrinol Metabol 2005; 90(8): 4955-62. DOI: 10.1210/jc.2004-2527

[4] Wajchenberg BL, Mendonca BB, Liberman B, et al. Ectopic 
adrenocorticotropic hormone syndrome. Endocr Rev 1994; 15(6): 752-87. DOI: $10.1210 /$ er.15.6.752

[5] Salgado LR, Fragoso MCBV, Knoepfelmacher M, et al. Ectopic ACTH syndrome: Our experience with 25 cases. Eur J Endocrinol 2006; 155(5): 725-33. DOI: 10.1530/eje.1.02278

[6] Momah T, Patel A, Ahulwalia M. Small cell carcinoma of the lung with paraneoplastic features. Commun Oncol 2009; 6(6): 255-61. DOI: 10.1016/S1548-5315(11)70348-5

[7] Doi M, Sugiyama T, Izumiyama H, Yoshimoto T, Hirata Y. Clinical features and management of ectopic ACTH syndrome at a single institute in Japan. Endocr J 2010; 57(12): 1061-9. DOI: $10.1507 /$ endocrj.K10E-265

[8] Sarlis NJ, Chanock SJ, Nieman LK. Cortisolemic indices predict severe infections in Cushing syndrome due to ectopic production of adrenocorticotropin. J Clin Endocrinol Metabol 2000; 85(1): 42-7. DOI: 10.1210/jc.85.1.42
[9] Putignano P, Kaltsas G, Korbonits M, et al. Alterations in serum protein levels in patients with Cushing's syndrome before and after successful treatment. J Clin Endocrinol Metabol 2000; 85(9): 3309-12. DOI: 10.1210/jc.85.9.3309

[10] Isidori AM, Lenzi A. Ectopic ACTH syndrome. Arq Bras Endocrinol Metabol 2007; 51(8): 1217-25. DOI: $10.1590 /$ S0004-27302007000800007

[11] Aron DC, Raff H, Findling JW. Effectiveness versus efficacy: the limited value in clinical practice of high dose dexamethasone suppression testing in the differential diagnosis of adrenocorticotropin-dependent Cushing's syndrome. J Clin Endocrinol Metabol 1997; 82(6): 1780-5. DOI: 10.1210/jcem.82.6.3991

[12] Terzolo M, Reimondo G, Ali A, et al. Ectopic ACTH syndrome: Molecular bases and clinical heterogeneity. Ann Oncol 2001; 12(suppl-2): S83-S7. DOI: 10.1093/annonc/12.suppl_2.S83 